\title{
The Effect of Homocysteine on the Secretion of Il-1ß, Il-6, Il-10, Il-12 and RANTES by Peripheral Blood Mononuclear Cells-An In Vitro Study
}

\author{
Magdalena Borowska ${ }^{1, *}$, Hanna Winiarska ${ }^{1}$, Marzena Dworacka ${ }^{1}$, Anna Wesołowska ${ }^{1}$, Grzegorz Dworacki ${ }^{2}$ \\ and Przemysław Łukasz Mikołajczak ${ }^{1}$ (D) \\ 1 Department of Pharmacology, Poznan University of Medical Sciences, 60-806 Poznan, Poland; \\ hwiniar@ump.edu.pl (H.W.); mdworac@ump.edu.pl (M.D.); anna.wesolowska@ump.edu.pl (A.W.); \\ przemmik@ump.edu.pl (P.Ł.M.) \\ 2 Department of Clinical Pathology, Poznan University of Medical Sciences, 60-355 Poznan, Poland; \\ gdwrck@ump.edu.pl \\ * Correspondence: magdaborowska@ump.edu.pl
}

Citation: Borowska, M.; Winiarska, H.; Dworacka, M.; Wesołowska, A.; Dworacki, G.; Mikołajczak, P.Ł. The Effect of Homocysteine on the Secretion of Il-1 $\beta$, Il-6, Il-10, Il-12 and RANTES by Peripheral Blood

Mononuclear Cells-An In Vitro Study. Molecules 2021, 26, 6671. https://doi.org/10.3390/ molecules26216671

Academic Editors: Raluca Maria Pop, Stefan Cristian Vesa and Ada Popolo

Received: 4 October 2021

Accepted: 1 November 2021

Published: 4 November 2021

Publisher's Note: MDPI stays neutral with regard to jurisdictional claims in published maps and institutional affiliations.

Copyright: (c) 2021 by the authors. Licensee MDPI, Basel, Switzerland. This article is an open access article distributed under the terms and conditions of the Creative Commons Attribution (CC BY) license (https:// creativecommons.org/licenses/by/ $4.0 /)$.

\begin{abstract}
The contemporary theory of the inflammatory-immunological pathomechanism of atherosclerosis includes the participation of interleukin-1 $\beta$ (Il), Il-6, Il-10, Il-12, RANTES, and homocysteine in this process. The knowledge on the direct effect of hyperhomocysteinemia on inflammatorystate-related atherosclerosis is rather scarce. Our study is the first to account for the effects of homocysteine on the secretion of Il-10 and RANTES in vitro conditions. For this purpose, human mitogen-stimulated peripheral blood mononuclear cells (PBMNCs) were cultured in vitro and exposed to homocysteine at high concentrations. Subsequently, the concentrations of cytokines were assayed in the cell culture supernatant using flow cytofluorimetry. It has been shown that, in the presence of homocysteine, the secretion of IL-1, IL-6 and RANTES by PBMNCs was increased, whereas IL-10 concentration was significantly lower than that of the supernatant derived from a mitogenstimulated cell culture without homocysteine. The secretion of Il-12 by PBMNCs exposed exclusively to mitogen, did not differ from homologous cells also treated with homocysteine. Therefore, in our opinion, high-concentration homocysteine affects the progression of atherosclerosis by increasing the secretion of proinflammatory cytokines secreted by PBMNCs, such as Il-1 $\beta$, Il-6, RANTES, and by attenuating the secretion of Il-10.
\end{abstract}

Keywords: homocysteine; Il-1ß; Il-6; Il-12; Il-10; RANTES

\section{Introduction}

Progressive atherosclerosis is a major causative factor in ischemic heart disease, myocardial infarction, stroke and other atherosclerosis-related complications [1]. The dramatically high mortality due to the process of atherosclerosis has encouraged us to pursue detailed research on all aspects of the pathogenesis of this process. It is known that the pathogenesis of atherosclerosis, at both the level of its initiation and its progression, involves a chronic mild inflammatory process. The current concept of the development of vascular complications includes the participation of numerous cytokines, which are treated as important elements of the pathogenesis of inflammation [2]. It should be emphasized that an increased secretion of Il-1 $\beta$, Il-6, Il-12 and RANTES chemokines and, at the same time, a reduced secretion of anti-inflammatory Il-10 due to hypercholesterolaemia, oxidative stress and hyperglycaemia, resulted in vascular wall damage and the progression of atherosclerosis [3-5]. The involvement of these mediators has already been observed in the early stages of atherogenesis, as well as in the progression of atherosclerosis $[4,6,7]$.

The contemporary theory of the inflammatory-immunological pathomechanism of atherosclerosis includes the participation of not only numerous cytokines, but also homocysteine in this process at almost every stage of the formation of the atherosclerotic 
plaque [8]. The role of proatherogenic homocysteine and cytokines has already been welldocumented in many publications. The correlation between homocysteine levels and the concentration and expression of some cytokines and pro-inflammatory and proatherogenic factors has been previously demonstrated: Il-6 [9], Il-1 $\beta$, Il-8, Il-12 [10], Il-10 [11] and RANTES $[12,13]$. However, the evidence of a direct link between hyperhomocysteinemia and the generation of an immune response leading to the exacerbation or suppression of cytokine secretion is unclear. Therefore, in vitro studies were conducted to investigate the effect of homocysteine on the secretion of selected cytokines by peripheral blood mononuclear cells. To date, there have been no reports detailing the direct effect of homocysteine on the secretion of Il-10 and RANTES chemokines by PBMNCs. The concentration of homocysteine is a modifiable proatherogenic factor; therefore, the identification of a possible direct link between hiperhomocysteinemia and Il-1 $\beta$, Il-6, Il-10, Il-12 and RANTES secretion by PBMNCs could be of particular importance, considering the constantly increasing number of patients suffering from civilization diseases closely related to atherosclerosis.

\section{Results}

It has been shown that the secretion of Il- $1 \beta$, Il- 6 and RANTES by mitogen-stimulated PVMNCs increases $(p \leq 0.05)$ in the presence of homocysteine (Figures 1-3).

At the same time, the concentration of IL-10 in a supernatant derived from a mitogenstimulated cell culture in the presence of homocysteine is significantly lower $(p \leq 0.05)$ than in a supernatant derived from a mitogen-stimulated cell culture without the addition of homocysteine to the medium (Figure 4).

The secretion of Il-12 by cells coming from healthy individuals exposed exclusively to mitogen did not differ from homologous cells that were also treated with homocysteine (Figure 5).

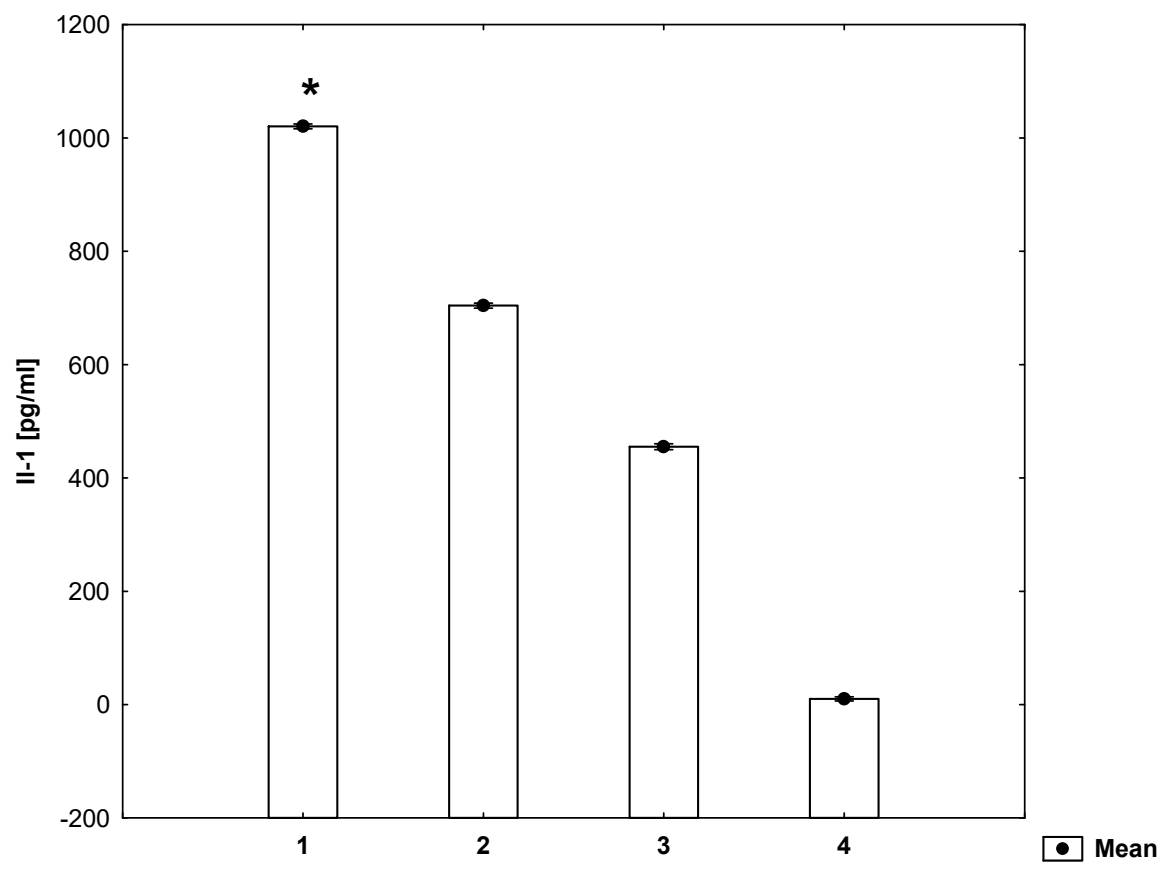

Figure 1. Concentrations of Il-1 $\beta$ in the cell culture supernatant (ANOVA). 1 -cell suspension + mitogen + homocysteine, 2 - cell suspension + mitogen, 3 - cell suspension, 4 -medium. ${ }^{*}$ statistically significant difference compared to every other group for $p \leq 0.05$. 


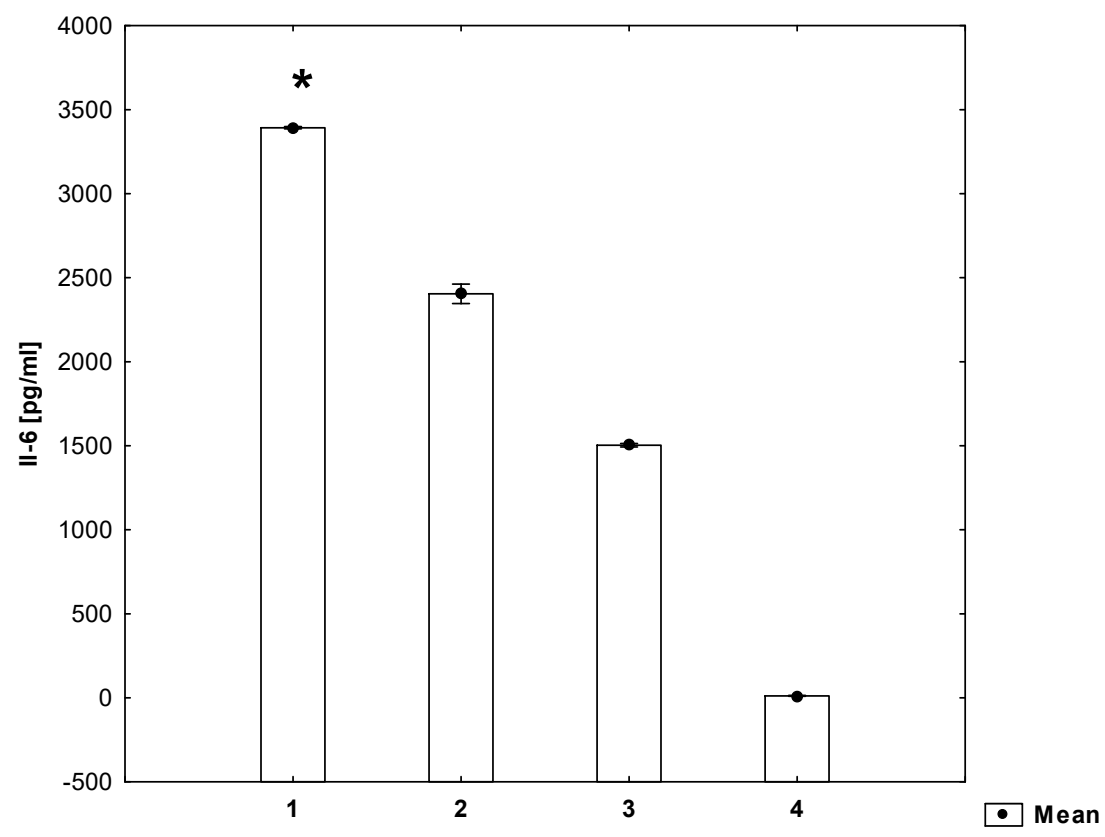

Figure 2. Concentrations of Il-6 in the cell culture supernatant (ANOVA). 1 -cell suspension + mitogen + homocysteine, 2-cell suspension + mitogen, 3-cell suspension, 4 -medium. * statistically significant difference compared to every other group for $p \leq 0.05$.

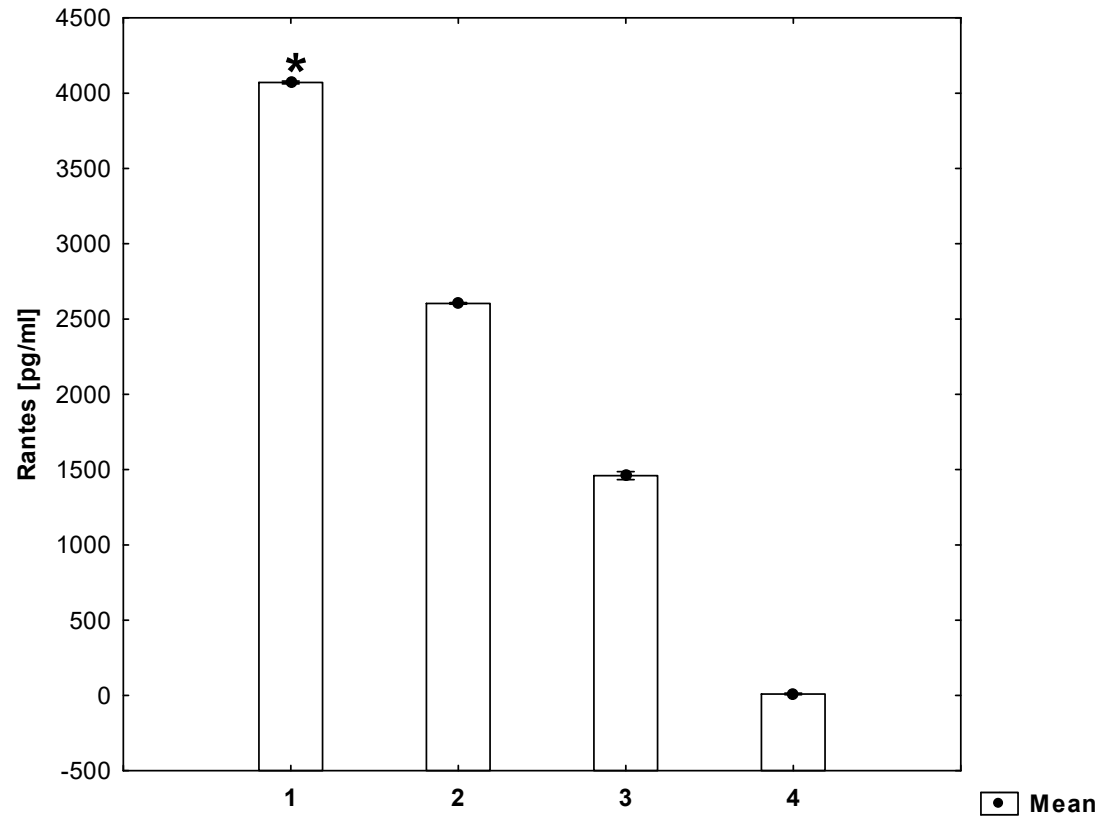

Figure 3. Concentrations of RANTES in the cell culture supernatant (ANOVA). 1 -cell suspension + mitogen + homocysteine, 2-cell suspension + mitogen, 3-cell suspension, 4 -medium. * statistically significant difference compared to every other group for $p \leq 0.05$. 


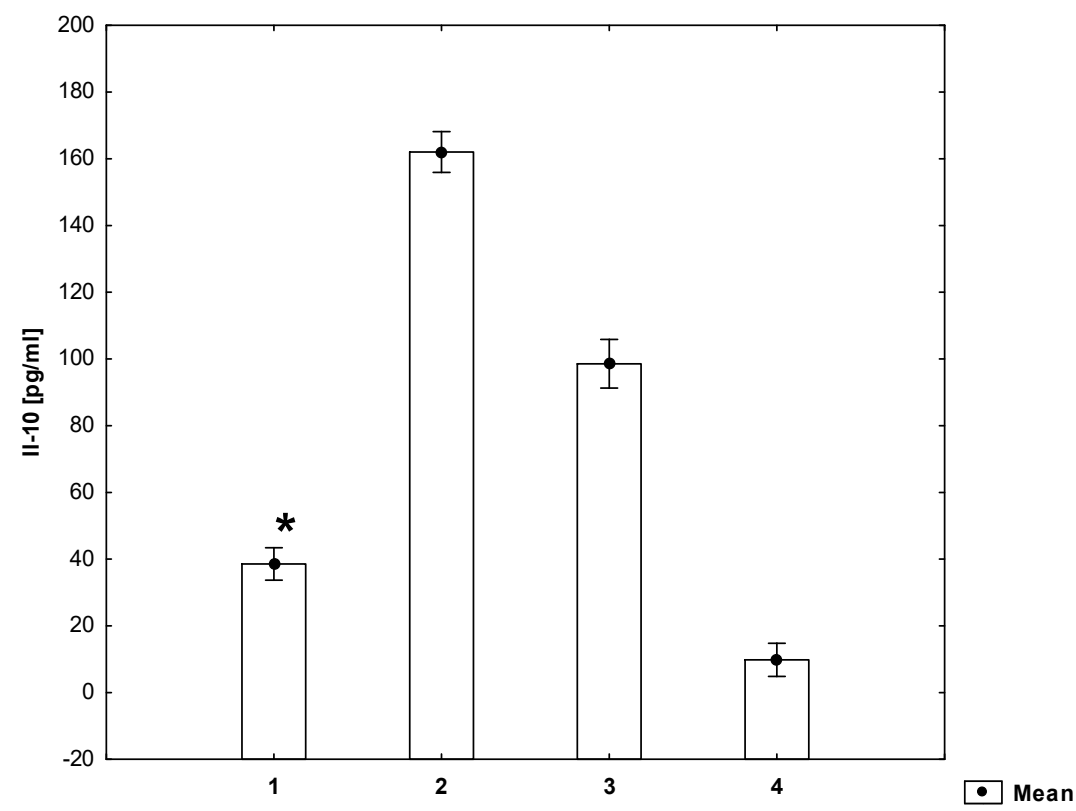

Figure 4. Concentrations of Il-10 in the cell culture supernatant (ANOVA). 1 - cell suspension + mitogen + homocysteine, 2-cell suspension + mitogen, 3-cell suspension, 4-medium. * statistically significant difference compared to every other group for $p \leq 0.05$.

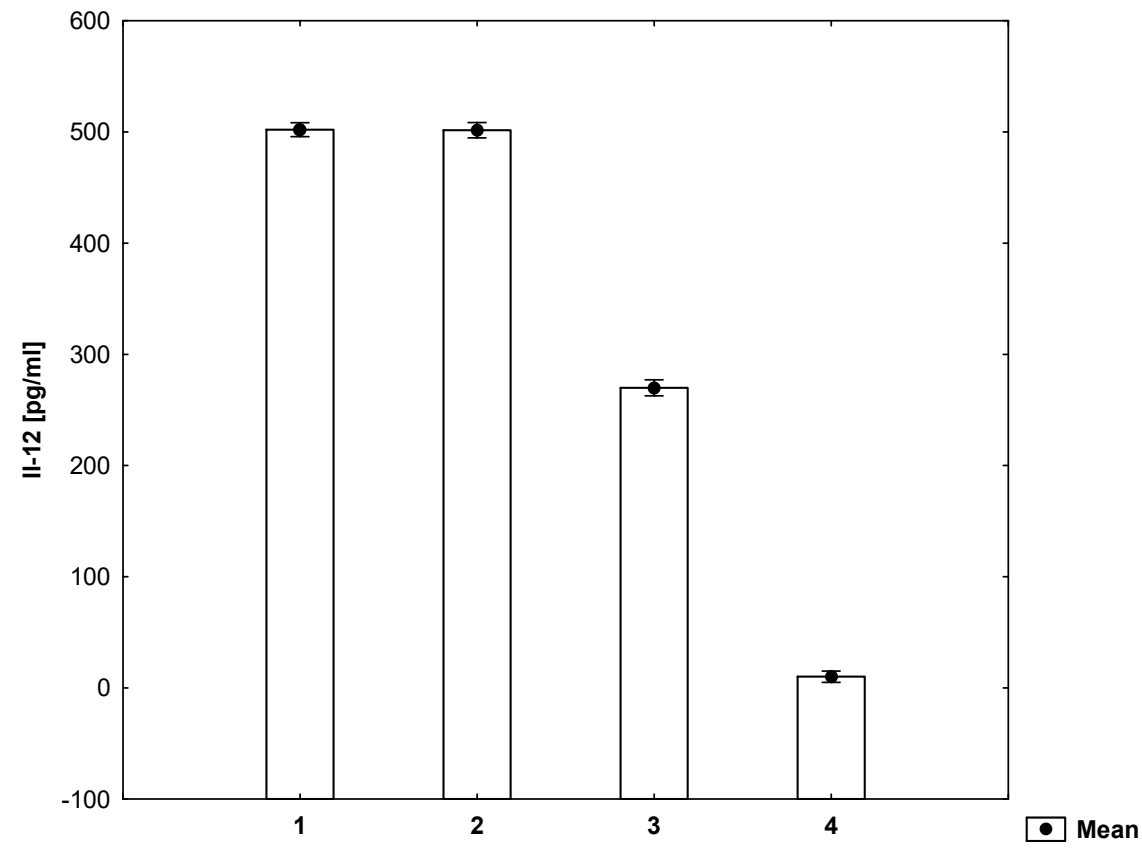

Figure 5. Concentrations of Il-12 in the cell culture supernatant (ANOVA). 1-cell suspension + mitogen + homocysteine, 2-cell suspension + mitogen, 3-cell suspension, 4-medium.

Figures 6-9 demonstrate examples of cytometry graphs for patients that are representative of each examined group. 

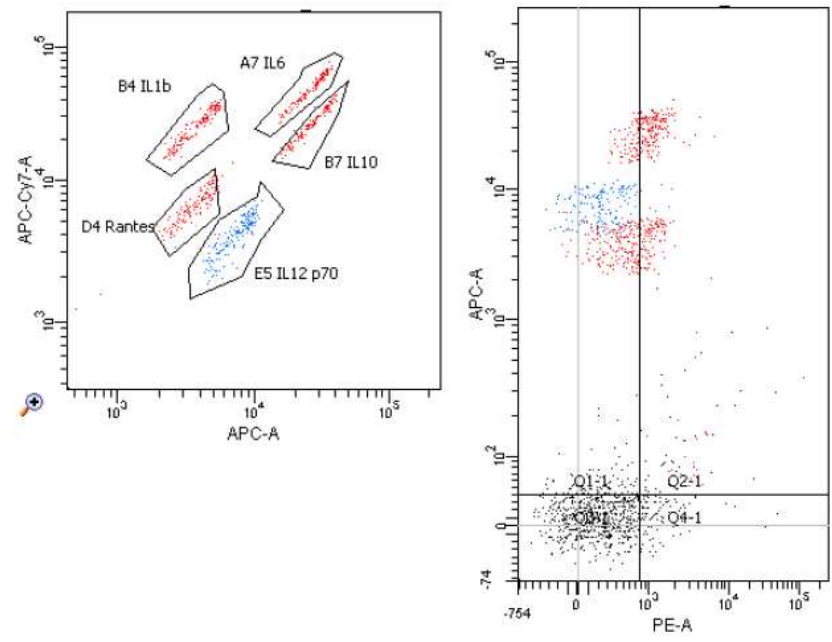

Figure 6. Il-1 $\beta$, Il-6, Il-12, Il-10 and RANTES expression in cell suspension with mitogen and homocysteine (Flow Cytometry raw data for a single patient).
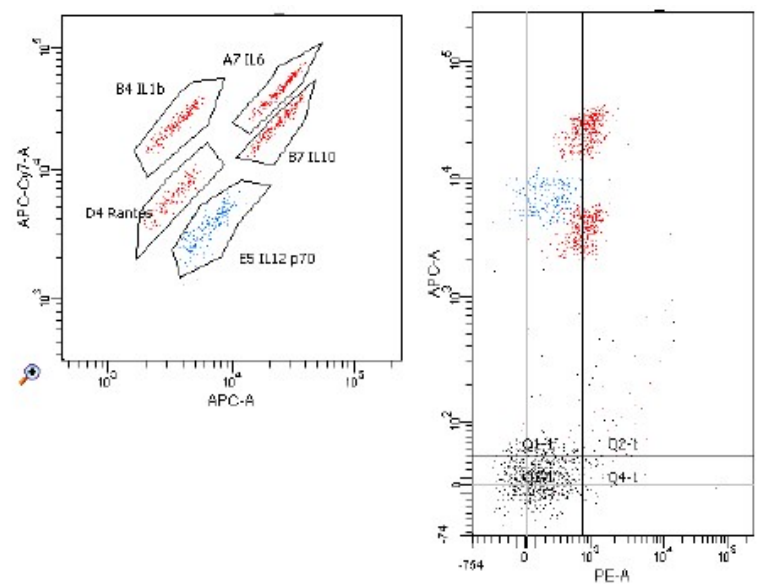

Figure 7. Il-1 $\beta$, Il-6, Il-12, Il-10 and RANTES expression in cell suspension with mitogen (Flow Cytometry raw data for a single patient).
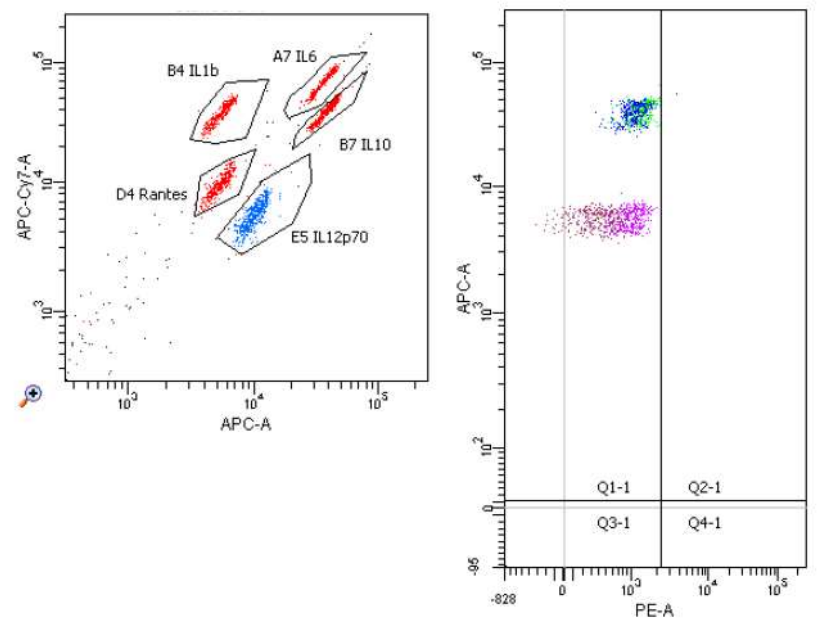

Figure 8. Il-1 $\beta$, Il-6, Il-12, Il-10 and RANTES expression in cell suspension (Flow Cytometry raw data for a single patient). 

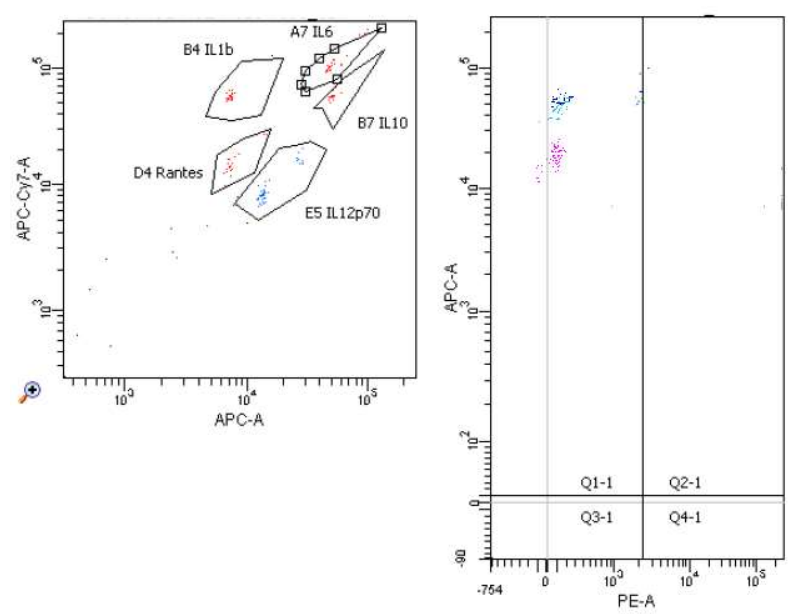

Figure 9. Il-1 $\beta$, Il-6, Il-12, Il-10 and RANTES expressions in medium (Flow Cytometry raw data for a single patient).

\section{Discussion}

Studies conducted in recent years have indicated a close relationship between atherosclerosis and immunologic processes in the vascular wall cells which were influenced by, e.g., interleukins, chemokines and adipocytokines [14-16], as well as hyperhomocysteinemia [17]. It is well known that proatherogenic Il- $1 \beta$ has the capacity to stimulate the chemokines, Il- $1 \beta$, Il-2, Il-6 secretion and to activate the inducible nitric oxide synthase, which enhances the formation of reactive oxygen species [18]. Moreover, Il-1 $\beta$ and Il-6 have been found to enhance the migration and proliferation of Vascular Smooth Muscle Cells (VSMC) and the synthesis of adhesins such as Vascular Cell Adhesion Molecule 1 (VCAM-1) and Intracellular Cell Adhesion Molecule 1 (ICAM-1) [19,20]. Additionally, Il-6 is a major factor in the hepatocytes stimulation, inducing the $C$ reactive protein (CRP) and fibrinogen secretion, which are recognized as the markers and components of inflammatory response occurring during atherogenesis [21,22]. The anti-inflammatory role of Il-10 includes the inhibition of the secretion of the pro-inflammatory Il- $1 \beta$, Il- 6 , Il- 8 , Il- 12 and TNF- $\alpha$ secretion by Th1, as well as the induction of Th2-type response, resulting in an increased secretion of Il-4, Il-5, Il-10, Il-13 [19]. It is noteworthy that Il-10 participates in the regulation of the expression of proinflammatory particles (Il-1 $\beta$, Il- 6 , tissue factor, TF), adhesion molecules (VCAM-1, ICAM-1), and chemotactic factors (Il-8) [19]. Low levels of Il-10 are, therefore, associated with atherosclerosis and are considered to be one of the non-classical proatherogenic factors [23]. The role of RANTES in the atherosclerotic process consists of the involvement of this chemokine in the process of the recruitment of inflammatory cells, i.e., $\mathrm{T}$ cells, monocytes and macrophages to the vessel wall [24-26]. The effect is an increase in the vascular smooth muscle proliferation and the dynamics of the plaque formation, which have a favourable influence on its stabilization $[27,28]$. The mechanism by which homocysteine promotes atherosclerosis includes the increased proliferation of vascular smooth muscle cells, as well as the increase in collagen synthesis and its deposition in the vascular wall [29]. The vascular toxicity of homocysteine has been linked to the impaired endothelial production of nitric oxide, and the overproduction of oxidative radicals that induce intimal injury [30]. In addition, homocysteine occurring as a thiolactone, a highly reactive product of homocysteine oxidation, modulates gene expression in pathways that are important for vascular homeostasis and pathways that are linked to the hyperhomocysteinemia-induced endothelial dysfunction and vascular disease [31,32]. Homocysteine auto-oxidation has been shown to generate the superoxide anion radicals that support the oxidation of lowdensity lipoproteins [33]. In view of these pro-atherogenic effects, hyperhomocysteinemia is considered a very important modifiable risk factor for cardiovascular diseases [34]. Previously, an in vivo study demonstrated the correlation between homocysteine blood concentration and the concentration and expression of cytokines and proinflammatory and 
proatherogenic factors, such as Il-6 [35], Il-1 $\beta$, Il-8, Il-12 [10], Il-10 [11] and RANTES [12,13]. However, the evidence of a direct link between hyperhomocysteinemia and the induction of an immune response leading to the exacerbation or suppression of cytokine secretion by PBMNCs remains unclear. Our in vitro study demonstrated that homocysteine had the ability to stimulate PBMNCs to cytokine secretion. Homocysteine stimulates the secretion of interleukin $1 \beta$, interleukin 6 and RANTES chemokines. These studies provide direct evidence for the close relationship between high homocysteine levels in the blood and the intensity of inflammation. A kind of a logical continuity can be the result of the homocysteine-induced IL-10 secretion. The expression of Il-10 was clearly suppressed in the presence of this aminoacid. Considering the antiatherogenic profile of IL-10, the presence of this cytokine in low-concentrations is considered to be a favourable condition for the progression of atherosclerosis and can be even referred to as a proatherogenic factor. Holven et al., [9] demonstrated a hyperhomocysteinemia-dependent decrease in the IL-10 secretion. The mechanism of this is not fully understood. It was documented that homocysteine, especially at concentrations equal to or higher than $100 \mu \mathrm{mol} / \mathrm{L}$, induced the mRNA and protein expressions of inflammatory cytokines [10] and that homocysteinerelevant transcriptional signaling was dependent on class 1 transcriptional factors, such as HSF, MEF2, NF-AT, NF-kB, KLF4. The hyperhomocysteinemia not only induced the secretion of Il-1 $\beta$, Il-6, RANTES by monocytes, but also promoted inflammation via the $\mathrm{TNF} \alpha$ induction, and subsequent MEF2 and NF- $\mathrm{KB}$ transactivation [36]. In addition, hyperhomocysteinemia reduced the expression of anti-inflammatory genes, i.e., PPAR $\gamma$ and PPAR $\alpha$ in human monocytes [37]. Il-10 secretion by monocytes was closely related to the activation of PPAR $\gamma$ [38]. The last observation seems to be confirmed by our experiment result, which showed that the Il-10 concentration in homocysteine-containing medium was significantly lower than in the control supernatant.

The results of our own investigation into the impact of high homocysteine concentrations on the immune response by the secretion of interleukin 12 by PBMNCs have proved surprising, as no significant homocysteine action was observed in this regard, although the production of this cytokine was regulated by the NF- $k B$ activity. However, the NF-

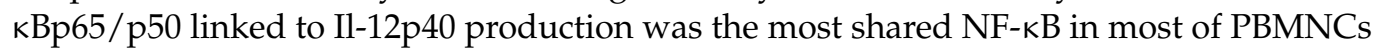
(T-cells, monocytes, NKT-cells) [39], while NF-kBp50/c-Rel linked to Il-12p35 production was present mainly in B-cells [40] which made up only a few percent of all PBMCs. This suggests that homocysteine was mainly responsible for Il-12p40 production by PBMCs, much less than for Il-12p35 and this disproportionately affected any significant increase in Il-12p70. Moreover, the Flex Set test used for the study was focused on the Il-12p70 evaluation, but not on $\mathrm{p} 40$ subunit.

\section{Materials and Methods}

\subsection{Examined Subjects}

The peripheral blood samples from ten healthy volunteers ( 6 males, 4 females, $42-50$ years of age, BMI-21.5-26.6, blood pressure below 140/90 mmHg, non-smokers, alcohol consumption $<70 \mathrm{~g}$ per week) were collected by the puncture of the peripheral vein into a tube containing EDTA (Sarsted, Nümbrecht, Germany). The volunteers were identified as the outpatients of general practitioners in Poznan (Poland). Before they were eligible for the study, a complete physical examination and laboratory evaluation were performed. Subjects with a history of infections, chronic or acute inflammatory diseases, organ dysfunction (kidney, liver, heart renal failure, thyroid gland disease or anaemia), as well as persons treated with folic acid, vitamin B6 or vitamin B12, were excluded from this study.

\subsection{The Isolation of Lymphocytes and Peripheral Blood Monocytes}

PBMNCs were isolated from the peripheral blood and taken into a tube containing EDTA. The blood was diluted with buffered saline solution of PBS (Sigma-Aldrich, St. Louis, MO, USA) at the ratio of 1:1, laminated in a centrifuge tube on the LymphoPaque reagent (Genaxxon bioscience, Ulm, Germany) and centrifuged for $20 \mathrm{~min}, 400 \times g$ 
at room temperature. The cells were washed with a PBS solution and suspended in an RPMI-1640 (Merck KGaA, Darmstad, Germany) culture medium for further analysis. The final concentration of the cell suspension in the medium was $2 \times 10^{6} \mathrm{~mL}$. The density of the cell suspension was assessed in the Thoma hematocytic chamber. Cell viability was checked with the trypan blue exclusion test (Trypan Blue solution, Sigma-Aldrich, St. Louis, MO, USA).

\subsection{Cell Cultures}

$72 \mathrm{~h}$ cultures were carried out on sterile 96-well cell culture plates under $5 \% \mathrm{CO}_{2}$ in air at $37^{\circ} \mathrm{C}$. $200 \mu \mathrm{L}$ of the cell suspension was placed in the wells, and, subsequently, a mitogenic factor consisting of phytohemagglutinin (PHA, Sigma-Aldrich, St. Louis, MO, USA) at the final concentration of a $2.5 \mu \mathrm{g} / \mathrm{mL}$ and homocysteine solutions (Sigma-Aldrich) were added. A freshly prepared solution of homocysteine at the final concentration of $185 \mu \mathrm{mol} / \mathrm{L}$ was used in the study. Our decision to use homocysteine at the concentration of $185 \mathrm{umol} / \mathrm{L}$ was based on the results of the pilot study, in addition to the results published by Su et al. [10]. The controls were wells containing either the culture medium or the cell suspension alone, plus wells containing the cell suspension with the addition of homocysteine-free PHA of equivalent volume.

The final composition of the contents of the wells prepared for individual subjects was as follows:

$200 \mu \mathrm{L}$ of the cell suspension, $10 \mu \mathrm{L}$ of PHA, $40 \mu \mathrm{L}$ of a $185 \mu \mathrm{mol} / \mathrm{L}$ homocysteine solution, $240 \mu \mathrm{L}$ of the cell suspension, $10 \mu \mathrm{L}$ of PHA, $240 \mu \mathrm{L}$ of the cell suspension, $250 \mu \mathrm{L}$ of the RPMI medium.

Immediately after the completion of the culture period, the samples were centrifuged and the supernatant was stored at $-80{ }^{\circ} \mathrm{C}$ for further assays.

All procedures performed in studies involving human participants were in accordance with the ethical standards of the institutional and/or national research committee (the Ethics Committee of the Poznan University of Medical Sciences nr 1286/06 (7 December 2006) and 1069/07 (6 December 2007) and all participants provided written informed consent.

The methodology determined the concentration of Il-1 $\beta$, Il-6, Il-10, Il-12 and RANTES in cell supernatants

The quantitative analysis of Il-1 $\beta$, Il-6, Il-10, Il-12 and RANTES was based on the flow cytofluorimetry method using Human Il-1 $\beta$, Il-6, Il-10, Il-12, RANTES Flex Set tests (Becton Dickinson Bioscience, Franklin Lakes, NJ, USA). The analysis included adding beads covered with antibodies (capture beads) directed against the cytokines to the cell culture supernatant. Each population of the capture beads was characterized by a welldefined position in the matrix diagram of FL3 and FL4 fluorescence channels, which made it possible to distinguish them. Subsequently, a solution of antibodies conjugated to the fluorescence-based indicator PE, i.e., phycoerythrin, was added. Both types of antibodies were specific for other binding sites of the test molecules, and the fluorescence of the phycoerythrin-labelled antibodies was directly proportional to the concentration of the cytokines tested. The last stage was measuring the fluorescence of the indicator conjugated to the antibody. At the same time, serial dilution of the standard solutions were made and subjected to the same procedure as the analysed samples. The analysis of the serial dilution of standard solutions produced a standard curve, which was used to calculate the concentration of test molecules in the sample. After the flow cytofluorimetry was performed, graphs showing the number of the cytokines examined were produced. The data were then analysed using FCAP ArrayTM Software (Becton Dickinson) to obtain cytokine concentration values.

The intra- and inter-assay CV was:

Il-1 1 CV-10\%, 8\%, 7\% and CV-3\%, 2\%, 4\%, Il-6 CV-6\%, 6\%, 8\% and CV-3\%, 3\%, 2\%, Il-10 CV-6\%, 10\%, 11\% and CV-6\%, 2\%, 3\%, Il-12 CV-4\%, 2\%, 3\% and CV-2\%, 5\%, 3\%, RANTES CV-10\%, 7\%, 3\% and CV-4\%, 5\%, 3\%. 


\subsection{Statistical Analysis}

Results are expressed as mean \pm SD. A comparison of variables between the examined groups was performed using ANOVA (parametric distribution) with Sheffe's post hoc test. All statistical analyses were performed using Statistica 6.0 (StatSoft, Inc., Dell, Round Rock, TX, USA). A $p$-value $\leq 0.05$ was considered statistically significant.

\section{Conclusions}

To summarise the results of our research, homocysteine should be considered a proatherogenic factor, which plays a significant role in the progression of atherosclerosis by directly triggering the inflammatory response by increasing the secretion of Il- $1 \beta$, Il- 6 , RANTES and attenuating IL-10 secretion by PBMNCs.

Author Contributions: Conceptualization-M.B., M.D., G.D., P.Ł.M.; Data curation-H.W., M.D., A.W.; Formal analysis-M.B., M.D., A.W.; Investigation-M.B., H.W., M.D.; Methodology-M.B., G.D.; Project administration-M.B., M.D.; Software-M.B., G.D.; Writing—original draft, M.B., H.W., M.D.; Writing-review and editing-M.B., P.E.M. All authors have read and agreed to the published version of the manuscript.

Funding: This work was supported by the Polish Ministry of Science and Higher Education [grant number 402357638].

Institutional Review Board Statement: The study was conducted according to the guidelines of the Declaration of Helsinki, and approved by the Ethics Committee of the Poznan University of Medical Sciences nr 1286/06 (7 December 2006) and 1069/07 (6 December 2007).

Informed Consent Statement: Informed consent was obtained from all subjects involved in the study.

Data Availability Statement: The data presented in this study are available on request from the corresponding authors.

Conflicts of Interest: The authors declare that they have no conflict of interest.

Sample Availability: Samples of the compounds are available from the authors.

\section{References}

1. Virani, S.S.; Alonso, A.; Benjamin, E.J.; Bittencourt, M.S.; Callaway, C.W.; Carson, A.P.; Chamberlain, A.M.; Chang, A.R.; Cheng, S.; Delling, F.N.; et al. 2020. Heart Disease and Stroke Statistics-2020 Update: A Report From the American Heart Association. Circulation 2020, 141, 139-596. [CrossRef]

2. Ramji, D.P.; Davies, T.S. Cytokines in atherosclerosis: Key players in all stages of disease and promising therapeutic targets. Cytokine Growth Factor Rev. 2015, 26, 673-685. [CrossRef] [PubMed]

3. Ali, M.; Mali, V.; Haddox, S.; AbdelGhany, S.M.; El-deek, S.E.M.; Abulfadl, A.; Khalid Matrougui, K.; Belmadani, S. Essential Role of IL-12 in Angiogenesis in Type 2 Diabetes. Am. J. Clin. Pathol. 2017, 187, 2590-2601. [CrossRef] [PubMed]

4. Tousoulis, D.; Oikonomou, E.; Economou, E.K.; Crea, F.; Kaski, J.C. Inflammatory cytokines in atherosclerosis: Current therapeutic approaches. Eur. Heart J. 2016, 37, 1723-1732. [CrossRef]

5. Herder, C.; Illig, T.; Baumert, J.; Müller, M.; Klopp, N.; Khuseyinova, N.; Meisinger, C.; Poschen, U.; Martin, S.; Koenig, W.; et al. RANTES/CCl5 gene polymorphisms, serum concentrations, and incident type 2 diabetes: Result from the MONICA/KORA Augsburg case-cohort study, 1984-2002. Eur. J. Endocrinol. 2008, 158, R1-R5. [CrossRef]

6. Fatkhullina, A.R.; Peshkova, I.O.; Koltsova, E.K. The Role of Cytokines in the Development of Atherosclerosis. Biochemistry 2016, 81, 1358-1370. [CrossRef]

7. Virani, S.S.; Nambi, V.; Hoogeveen, R.; Wasserman, B.A.; Coresh, J.; Gonzalez, F.; Chambless, L.E.; Mosley, T.H.; Boerwinkle, B.; Ballantyne, C.M. Relationship between circulating levels of RANTES (regulated on activation, normal T-cell expressed, and secreted) and carotid plaque characteristics: The Atherosclerosis Risk in Communities (ARIC) Carotid MRI Study. Eur. Heart J. 2011, 32, 459-468. [CrossRef] [PubMed]

8. Gokkusu, C.; Tulubas, F.; Unlucerci, Y.; Ozkok, E.; Umman, B.; Aydin, M. Homocysteine and pro-inflammatory cytokine concentrations in acute heart disease. Cytokine 2010, 50, 15-18. [CrossRef]

9. Holven, K.B.; Aukrust, P.; Retterstol, K.; Hagve, T.A.; Mørkrid, L.; Ose, L.; Nenseter, M.S. Increased levels of C-reactive protein and interleukin-6 in hyperhomocysteinemic subjects. Scand. J. Clin. Lab. Investig. 2006, 66, 45-54. [CrossRef]

10. Su, S.J.; Huang, L.W.; Pai, L.S.; Liu, H.W.; Chang, K.L. Homocysteine at pathophysiologic concentrations activates human monocyte and induces cytokine expression and inhibits macrophage migration inhibitory factor expression. Nutrient 2005, 21, 994-1002. [CrossRef] 
11. Dawson, H.; Collins, G.; Pyle, R.; Deep-Dixit, V.; Taub, D.D. The immunoregulatory effects of homocysteine and its intermediates on T-lymphocyte function. Mech. Ageing Dev. 2004, 125, 107-110. [CrossRef] [PubMed]

12. Holven, K.B.; Aukrust, P.; Holm, T.; Ose, L.; Nenseter, M.S. Folic acid treatment reduces chemokine release from peripheral blood mononuclear cells in hyperhomocysteinemic subjects. Arterioscler. Thromb. Vasc Biol. 2002, 22, 699-703. [CrossRef] [PubMed]

13. Sun, W.; Wang, G.; Zhang, Z.M.; Zeng, X.K.; Wang, X. Chemokine RANTES is upregulated in monocytes from patients with hyperhomocysteinemia. Acta Pharmacol. Sin. 2005, 26, 1317-1321. [CrossRef] [PubMed]

14. Libby, P.; Ridker, P.M.; Hansson, G.K. Inflammation and atherosclerosis. J. Am. Coll. Cardiol. 2009, 1, 2129-2138. [CrossRef] [PubMed]

15. Bäck, M.; Yurdagul, A.; Tabas, I.; Öörni, K.; Kovanen, P.T. Inflammation and its resolution in atherosclerosis: Mediators and therapeutic opportunities. Nat. Rev. Cardiol. 2019, 16, 389-406. [CrossRef]

16. Packard, R.R.; Libby, P. Inflammation in atherosclerosis: From vascular biology to biomarker discovery and risk prediction. Clin. Chem. 2008, 54, 24-38. [CrossRef]

17. Akalin, A.; Alatas, O.; Colak, O. Relation of plasma homocysteine levels to atherosclerotic vascular disease and inflammation markers in type 2 diabetic patients. Eur. J. Endocrinol. 2008, 158, 47-52. [CrossRef]

18. Kanno, K.; Hirata, Y.; Imai, T.; Iwashina, M.; Marumo, F. Regulation of inducible nitric oxide synthase gene by interleukin-1 beta in rat vascular endothelial cells. Am. J. Physiol. 1994, 267, 2318-2324. [CrossRef]

19. Tedgui, A.; Mallat, Z. Anti-inflammatory mechanism in vascular wall. Circ. Res. 2001, 88, 877-887. [CrossRef]

20. Von der Thüsen, J.H.; Kuiper, J.; Van Berkel, T.J.; Biessen, E.A. Interleukins in atherosclerosis: Molecular pathways and therapeutic potential. Pharmacol. Rev. 2003, 55, 133-166. [CrossRef] [PubMed]

21. Eklund, C.M. Proinfalmmatory cytokines in CRP baseline regulation. Adv. Clin. Chem. 2009, 48, 111-136.

22. Didion, S.P. Cellular and Oxidative Mechanisms Associated with Interleukin-6 Signaling in the Vasculature. Int. J. Mol. Sci. 2017, 18, 2563. [CrossRef] [PubMed]

23. Caligiuri, G.; Rudling, M.; Ollivier, V.; Jacob, M.P.; Michel, J.B.; Hansson, O. Interleukin 10 Deficiency increases Atherosclerosis, Thrombosis, and Low-density Lipoproteins in Apolipoprotein E Knockout Mice. Mol. Med. 2003, 9, 10-17. [CrossRef] [PubMed]

24. Zernecke, A.; Weber, C. Chemokines in the vascular inflammatory response of atherosclerosis. Cardiovasc. Res. 2010, 86, 192-201. [CrossRef] [PubMed]

25. Von Hundelshausen, P.; Koenen, R.R.; Sack, M.; Mause, S.F.; Adriaens, W.; Proudfoot, A.E.; Hackeng, T.M.; Weber, C. Heterophilic interactions of platelet factor 4 and RANTES promote monocyte arrest on endothelium. Blood 2005, 105, 924-930. [CrossRef]

26. Shanmugham, L.N.; Petrarca, C.; Castellani, M.L.; Frydas, S.; Vecchiet, J.; Conti, P.; Tete, S. Rantes potentiates human macrophage aggregation and activation responses to calcium ionophore (A23187) and activates arachidonic acid pathways. J. Biol. Regul. Homeost. Agents 2006, 20, 15-23.

27. Barlic, J.; Murphy, M. ; Murphy, M. Chemokine regulation of atherosclerosis. J. Leukocyte Biol. 2009, 82, 226-236. [CrossRef]

28. Zhang, Z.; Dong, J.; Lobe, C.G.; Gong, P.; Liu, J.; Liao, L. CCR5 facilitates endothelial progenitor cell recruitment and promotes the stabilization of atherosclerotic plaques in ApoE-/- mice. Stem. Cell Res. Ther. 2015, 19, 6-36. [CrossRef] [PubMed]

29. Pushpakumar, S.; Kundu, S.; Sen, U. Endothelial dysfunction: The link between homocysteine and hydrogen sulfide. Curr. Med. Chem. 2014, 21, 3662-3672. [CrossRef]

30. Signorello, M.G.; Segantin, A.; Passalacqua, M.; Leoncini, G. Homocysteine decreased platelet NO level via protein kinase C activation. Nitric Oxide 2009, 20, 104-113. [CrossRef]

31. Gurda, D.; Handschuh, L.; Kotkowiak, W.; Jakubowski, H. Homocysteine thiolactone and N-homocysteinylated protein induce pro-atherogenic changes in gene expression in human vascular endothelial cells. Amino Acids 2015, 47, 1319-1339. [CrossRef]

32. Esse, R.; Barroso, M.; Tavares de Almeida, I.; Castro, R. The contribution of homocysteine metabolism disruption to endothelial dysfunction: State-of-the-Art. Int. J. Mol. Sci. 2019, 20, 867. [CrossRef] [PubMed]

33. Seo, H.; Oh, H.; Park, H.; Park, M.; Jang, Y.; Lee, M. Contribution of dietary intakes of antioxidants to homocysteine-induced low density lipoprotein (LDL) oxidation in atherosclerotic patients. Yonsei Med. J. 2010, 51, 526-533. [CrossRef] [PubMed]

34. Ganguly, P.; Sreyoshi, F.A. Role of homocysteine in the development of cardiovascular disease. Nutr. J. 2015, 14, 6. [CrossRef]

35. Araki, A.; Hosoi, T.; Orimo, H.; Ito, H. Association of plasma homocysteine with serum interleukin-6 and C-peptide levels in patients with type 2 diabetes. Metabolism 2005, 54, 809-814. [CrossRef] [PubMed]

36. Meng, S.; Ciment, S.; Jan, M.; Tran, T.; Pham, H.; Cueto, R.; Yang, X.F.; Wang, H. Homocysteine induces inflammatory transcriptional signaling in monocytes. Front. Biosci. 2013, 1, 685-695. [CrossRef]

37. Yideng, J.; Zhihong, L.; Jiantuan, X.; Jun, C.; Guizhong, L.; Shuren, W. Homocysteine-mediated PPAR alpha, gamma DNA methylation and its potential pathogenic mechanism in monocytes. DNA Cell Biol. 2008, 27, 143-150. [CrossRef] [PubMed]

38. Bouhlel, M.A.; Derudas, B.; Rigamonti, E.; Dievart, R.; Brozek, J.; Haulon, S.; Zawadzki, C.; Jude, B.; Torpier, G.; Marx, N.; et al. PPARgamma activation primes human monocytes into alternative M2 macrophages with anti-inflammatory properties. Cell Metab. 2007, 6, 137-143. [CrossRef] [PubMed]

39. Hayden, M.S.; Ghosh, S. Signaling to NF-kappaB. Genes Dev. 2004, 18, 2195-2224. [CrossRef]

40. Miyamoto, S.; Maki, M.; Schmitt, M.J.; Hatanaka, M.; Verma, I.M. Tumor necrosis factor alpha-induced phosphorylation of I kappa B alpha is a signal for its degradation but not dissociation from NF-kappa B. Proc. Natl. Acad. Sci. USA 1994, 91, 12740-12744. [CrossRef] 